1. Berson, E.L., et al. 1993. A randomized trial of vitamin A and vitamin E supplementation for retinitis pigmentosa. Arch. Ophthalmol. 111:761-772.

2. Grant, C.A., and Berson, E.L. 2001. Treatable forms of retinitis pigmentosa associated with systemic neurological disorders. Int. Ophthalmol. Clin. 41:103-110.

3. Takahashi, M., Miyoshi, H., Verma, I.M., and Gage, F.H. 1999. Rescue from photoreceptor degen eration in the rd mouse by human immunodeficiency virus vector-mediated gene transfer. J. Virol. 73:7812-7816

4. Ali, R.R., et al. 2000. Restoration of photoreceptor ultrastructure and function in retinal degeneration slow mice by gene therapy. Nat. Genet. 25:306-310.

5. Vollrath, D., et al. 2001. Correction of the retinal dystrophy phenotype of the RCS rat by viral gene transfer of Mertk. Proc. Natl. Acad. Sci. U. S. A. 98:12584-12589.

6. Acland, G.M., et al. 2001. Gene therapy restores vision in a canine model of childhood blindness. Nat. Genet. 28:92-95.

7. Kajiwara, K., et al. 1991. Mutations in the human retinal degeneration slow gene in autosomal dominant retinitis pigmentosa. Nature. 354:480-483.

8. Travis, G.H., et al. 1991. The human retinal degeneration slow (RDS) gene: chromosome assignment and structure of the mRNA. Genomics. 10:733-739.

9. Frasson, M., et al. 1999. Glial cell line-derived neurotrophic factor induces histologic and functional protection of rod photoreceptors in the $\mathrm{rd}$ / rd mouse. Invest. Ophthalmol. Vis. Sci. 40:2724-2734.

10. Bush, R.A., et al. 2004. Encapsulated cell-based intraocular delivery of ciliary neurotrophic factor in normal rabbit: dose-dependent effects on ERG and retinal histology. Invest. Ophthalmol. Vis. Sci. 45:2420-2430.

11. Uteza, Y., et al. 1999. Intravitreous transplantation of encapsulated fibroblasts secreting the human fibroblast growth factor 2 delays photoreceptor cell degeneration in Royal College of Surgeons rats. Proc. Natl. Acad. Sci. U. S. A. 96:3126-3131.

12. Frasson, M., et al. 1999. Retinitis pigmentosa: rod photoreceptor rescue by a calcium-channel blocker in the rd mouse. Nat. Med. 5:1183-1187.
13. Meyer, J.S., Katz, M.L., Maruniak, J.A., and Kirk, M.D. 2004. Neural differentiation of mouse embryonic stem cells in vitro and after transplantation into eyes of mutant mice with rapid retinal degeneration. Brain Res. 1014:131-144.

14. Otani, A., et al. 2004. Rescue of retinal degeneration by intravitreally injected adult bone marrow-derived lineage-negative hematopoietic stem cells. J. Clin. Invest. 114:765-774. doi:10.1172/ JCI200421686.

15. Grant, M.B., et al. 2002. Adult hematopoietic stem cells provide functional hemangioblast activity during retinal neovascularization. Nat. Med. 8:607-612.

16. Otani, A., et al. 2002. Bone marrow-derived stem cells target retinal astrocytes and can promote or inhibit retinal angiogenesis. Nat. Med. 29:1004-1010.

17. Chacko, D.M., et al. 2003. Transplantation of ocular stem cells: the role of injury in incorporation and differentiation of grafted cells in the retina. Vision Res. 43:937-946.

18. Leveillard, T., et al. 2004. Identification and characterization of rod-derived cone viability factor. Nat. Genet. 36:755-759.

\title{
Prostanoids and blood pressure: which way is up?
}

\author{
Helene Francois and Thomas M. Coffman
}

Division of Nephrology, Department of Medicine, Duke University and Durham Veterans Affairs Medical Center, Durham, North Carolina, USA.

\begin{abstract}
Members of the family of prostanoids, made up of prostaglandins and thromboxanes, are generated via COX-mediated metabolism of arachidonic acid. These lipid mediators exhibit wide-ranging biological actions that include regulating both vasomotor tone and renal sodium excretion. As COX inhibition is often associated with sodium retention leading to edema and hypertension, prostanoids appear to have a role in preventing the development of high blood pressure. On the other hand, prostaglandin $E_{2}$ $\left(\mathrm{PGE}_{2}\right)$ and $\mathrm{PGI}_{2}$ have also been implicated as determinants of renin secretion. A new study suggests that $\mathrm{PGI}_{2}$ plays a critical role in stimulating renin release and promoting hypertension following renal artery stenosis (see the related article beginning on page 805 ).
\end{abstract}

Prostanoids are generated by COX-mediated metabolism of arachidonic acid. These lipid mediators have a myriad of biological actions $(1,2)$. A role for prostanoids in the regulation of blood pressure was originally suggested by early observations that prostaglandins and thromboxanes affect vascular tone and renal excretory functions (3). Later, the impact of prostanoids upon blood pressure in humans was clearly demon-

Nonstandard abbreviations used: EP, E-prostanoid; IP, I-prostanoid;JGA, juxtaglomerular apparatus; NKCC2, Na-K-2Cl cotransporter 2; $\mathrm{PGE}_{2}$, prostaglan$\operatorname{din} \mathrm{E}_{2}$.

Conflict of interest: The authors have declared that no conflict of interest exists.

Citation for this article: J. Clin. Invest. 114:757-759 (2004). doi:10.1172/JCI200422929. strated through clinical experiences with NSAIDs. NSAIDs, among the most widely prescribed drugs worldwide, act by inhibiting COX enzymes and hence blocking prostanoid production. Sodium retention leading to edema and hypertension is often observed in patients treated with NSAIDs $(4,5)$. However, increased blood pressure after treatment with NSAIDs is observed primarily in patients with preexisting hypertension (6-8), suggesting a compensatory role for the prostanoid system in attenuating or preventing the development of high blood pressure.

Data from clinical trials suggest that nonselective NSAIDs, which inhibit both COX isoforms (COX-1 and -2), and selective COX-2 inhibitors (9-12) have similar propensities to cause hyperten- sion. The theory that COX-2-dependent prostanoids resist the development of hypertension is further supported by experiments showing that COX-2 inhibitors or the genetic absence of COX-2 markedly augment the vasoconstrictor actions of Ang II (13). Among the prostanoids, prostaglandin $\mathrm{E}_{2}\left(\mathrm{PGE}_{2}\right)$ and $\mathrm{PGI}_{2}$ are potent vasodilators that promote renal sodium excretion and thus are logical candidates to mediate these counter-regulatory functions. In this regard, studies in humans suggest that COX-2 may be specifically linked to the generation of $\mathrm{PGI}_{2}$ in the systemic circulation (14). The predominant inhibition of $\mathrm{PGI}_{2}$ by COX-2 inhibitors has been posited as an explanation for putative associations between COX-2 inhibitors and the development of cardiovascular complications (15), including hypertension $(16,17)$.

\section{Prostanoids and renovascular hypertension}

In this issue of the JCI, Fujino and associates show that the absence of the receptor for $\mathrm{PGI}_{2}$ (the I-prostanoid [IP] receptor) confers substantial resistance to the development of renovascular hypertension (18). Based on the discussion above, these findings may seem surprising. 


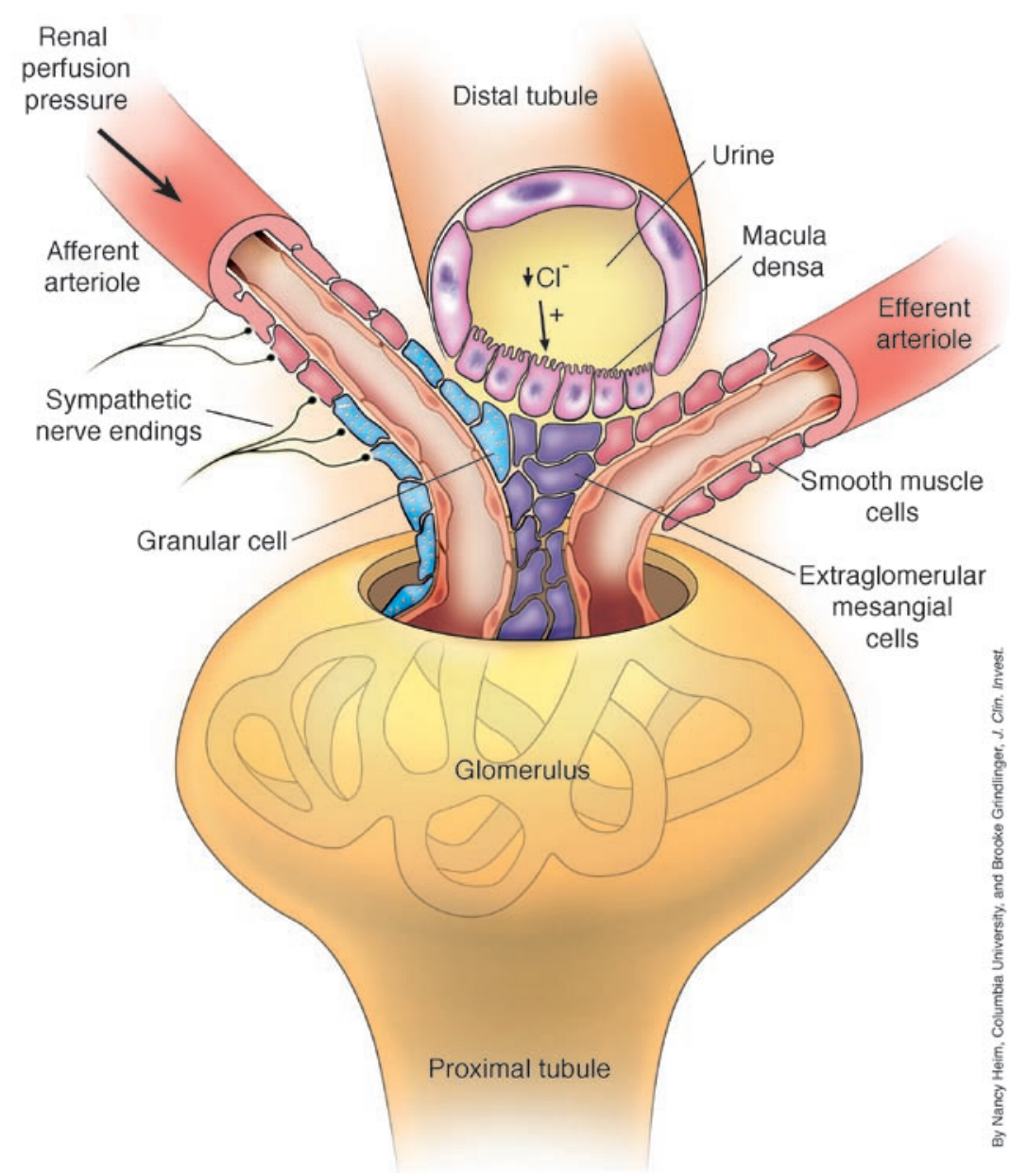

Figure 1

The juxtaglomerular apparatus. Integration of the regulated secretion of renin is carried out at the JGA. There are three major pathways regulating the secretion of renin by granular cells at the JGA: the baroreceptor, the macula densa mechanism, and direct stimulation by the sympathetic nervous system. The renal baroreceptor monitors renal perfusion pressure and signals an increase in renin when renal perfusion pressure falls. In the macula densa mechanism, macula densa cells sense the decrease in chloride ions in the filtrate in the distal tubule, thereby stimulating release of renin. Increased activity of renal sympathetic nerves directly stimulates renin release via activation of $\beta$ adrenergic receptors. Sympathetic innervation also modulates both the baroreceptor and macula densa mechanisms.

However, along with the well-characterized effects of prostanoids on vascular tone, the role of prostanoids in the regulation of renin release has long been recognized For example, studies dating back to the 1970s have documented potent actions of both $\mathrm{PGE}_{2}$ and $\mathrm{PGI}_{2}$ in stimulating renin secretion (19). These actions depend on the intracellular generation of cAMP. In this regard, the IP receptor, along with the E-prostanoid 2 (EP2) and EP4 receptors for $P_{G_{2}}$, signal via $G_{s}$ protein activation of adenyl cyclase (20). To test the role of individual prostanoid receptors in renovascular hypertension, Fujino et al. evaluated blood pressure and renin responses in mice lacking the IP receptor or one of the 4 individual EP receptors using a Goldblatt kidney model wherein a stenosis is created in one renal artery. The consequent reduction in renal blood flow stimulates synthesis and release of renin by granular cells of the juxtaglomerular apparatus (JGA) (Figure 1). The resulting generation of Ang II promotes vasoconstriction and impaired sodium excretion by the kidney. In the mice lacking IP receptors, stimulation of renin by renal artery stenosis and the subsequent development of hypertension were markedly attenuated.

\section{Prostanoids and renin release}

There are two major physiological controls for stimulating renin in vivo: the baroreceptor and the macula densa mechanisms. It has been suggested that both of these mechanisms depend on prostanoids and can be influenced by sympathetic innervation (21). In renovascular hypertension, the baroreceptor mechanism is the primary mechanism for stimulating renin release. In the presence of a critical stenosis of the renal artery, renal perfusion pressure drops, stimulating renin. The magnitude of renin release is inversely correlated with renal perfusion pressure (22). Although both $\mathrm{PGI}_{2}$ and $\mathrm{PGE}_{2}$ have been implicated in the baroreceptor response (23), the study by Fujino et al. (18) indicates that $\mathrm{PGI}_{2}$, acting through the IP receptor, is primarily responsible for this action. Moreover, a contribution of $\mathrm{PGE}_{2}$ seems to be clearly excluded as deficiency of any of the individual EP receptors had no impact on the development of hyperreninemia and hypertension (18).

While the baroreceptor mechanism regulating renin release has been localized to the kidney, identification of its precise nature has been elusive. Various models have been proposed to explain the mechanism for pressure sensing and consequent signal transduction, including direct stretch of the juxtaglomerular cells due to transmural pressure across the afferent arteriole (24) or indirect pathways involving secondary release of autocoids (25). Identification of a nonredundant role for IP receptors in the baroreceptor response may provide a means for developing a more explicit characterization of its molecular and cellular mechanisms. Further, these new findings raise a number of interesting questions. How does reduced intrarenal pressure activate COX-2 and enhance synthesis of $\mathrm{PGI}_{2}$ ? Which cell lineages are involved? As most studies have failed to identify IP receptor expression in juxtaglomerular cells $(26,27)$, the cellular targets for IP receptor actions that affect renin release also need to be defined. Because IP receptors are expressed on dorsal root ganglia (27) and renal nerves play a critical role in baroreceptor responses, it is possible that IP receptors may influence renin release by modulating sympathetic nerve activity.

The second major pathway for physiological regulation of renin is the so-called macula densa mechanism whereby cells at the macula densa sense a reduction of chloride ions in the filtrate within the distal tubule, thereby triggering renin release (28). In this circumstance, release of renin and the con- 
sequent generation of Ang II is believed to serve as a mechanism for enhancing renal sodium reabsorption in states of fluid volume depletion. The prevailing view of this mechanism has suggested that reduced chloride flux through $\mathrm{Na}-\mathrm{K}-2 \mathrm{Cl}$ cotransporter 2 (NKCC2) activates COX-2, thereby generating $\mathrm{PGE}_{2}$ (29). $\mathrm{PGE}_{2}$ then activates an EP receptor (probably EP4) on granular cells to stimulate renin release. Previous studies have clearly demonstrated the importance of COX-2 in the macula densa pathway (30). In addition, the activity of various components of this system has been demonstrated in isolated perfused macula densa segments (31) and juxtaglomerular cell lines (32). However, the role of these individual components in regulating renin release in the intact animal has not been unequivocally demonstrated.

Accordingly, Fujino and associates also carried out experiments to test for contributions of the IP and various EP receptors to the macula densa response by placing prostanoid receptor-deficient mice on a lowsalt diet and treating them with furosemide, which blocks chloride reabsorption by NKCC2 (18). Once again, stimulation of renin was attenuated in the IP-deficient mice but was unaffected in mice deficient in any of the individual EP receptors. Based on this result, the authors concluded that the IP receptor also delivers a critical signal for renin regulation by the macula densa mechanism. However, because there is no report of blood pressure monitoring in these studies, one must be somewhat circumspect about this conclusion. It is likely that the combination of a low-salt diet and furosemide administration affected blood pressure, potentially activating renin via baroreceptor mechanisms that are independent of the macula densa pathway. As discussed by the authors, there are also issues related to the genetic background of the EP4-deficient animals that may further confound interpretation of this result. Thus, further studies are required to define specific prostanoids and prostanoid receptors mediating renin release by the macula densa mechanism.

\section{Complex actions of prostanoids on blood pressure}

Taken together, these studies highlight the paradoxical nature of blood pressure regulation by prostanoids. The consequences of activation of the renin-angiotensin system by $\mathrm{COX}-2$-dependent generation of $\mathrm{PGI}_{2}$ are in direct opposition to its effects on renal vasculature and epithelia that lead to vasodilation and natriuresis. Moreover, it is not clear whether or how these apparently conflicting actions of $\mathrm{PGI}_{2}$ are differentially regulated. Normal blood pressure homeostasis clearly involves a balance among these divergent actions. Understanding how these elements are integrated remains a fundamental objective in this field. Characterizing factors affecting this balance should facilitate managing patients at risk for NSAID-induced hypertension and, conversely, may identify patients whose blood pressure control might actually benefit from prostanoid inhibition.

Address correspondence to: Thomas M. Coffman, Building 6/Nephrology (111I), Durham Veteran Affairs Medical Center, 508 Fulton Street, Durham, North Carolina 27705, USA. Phone: (919) 286-6947; Fax: (919) 286-6879; E-mail: tcoffman@acpub.duke.edu.

1. Oates, J.A., et al. 1988. Clinical implications of prostaglandin and thromboxane A2 formation (2). N. Engl. J. Med. 319:761-767.

2. Oates, J.A., et al. 1988. Clinical implications of prostaglandin and thromboxane A2 formation (1). N. Engl.J. Med. 319:689-698.

3. Dunn, M. 1987. The role of arachidonic acid metabolites in renal homeostasis. Non-steroidal anti-inflammatory drugs renal function and biochemical, histological and clinical effects and drug interactions. Drugs. 33(Suppl. 1):56-66.

4. Gurwitz, J.H., et al. 1994. Initiation of antihypertensive treatment during nonsteroidal anti-inflammatory drug therapy. JAMA. 272:781-786.

5. Johnson, A.G., Nguyen, T.V., and Day, R.O. 1994. Do nonsteroidal anti-inflammatory drugs affect blood pressure? A meta-analysis. Ann. Intern. Med. 121:289-300.

6. Whelton, A. 2002. COX-2-specific inhibitors and the kidney: effect on hypertension and oedema. J. Hypertens. 20 (Suppl. 6):S31-S35.

7. Frishman, W.H. 2002. Effects of nonsteroidal antiinflammatory drug therapy on blood pressure and peripheral edema. Am. J. Cardiol. 89:18D-25D.

8. de Leeuw, P.W. 1996. Nonsteroidal anti-inflammatory drugs and hypertension. The risks in perspective. Drugs. 51:179-187.

9. Ray, W.A., et al. 2002. COX-2 selective non-steroidal anti-inflammatory drugs and risk of serious coronary heart disease. Lancet. 360:1071-1073.

10. Solomon, D.H., Schneeweiss, S., Levin, R., and Avorn, J. 2004. Relationship between COX-2 specific inhibitors and hypertension. Hypertension. 44:140-145.

11. Bombardier, C., et al. 2000. Comparison of upper gastrointestinal toxicity of rofecoxib and naproxen in patients with rheumatoid arthritis. VIGOR Study Group. N. Engl. J. Med. 343:1520-1528, 2 pp. following 1528 .

12. Silverstein, F.E., et al. 2000. Gastrointestinal toxicity with celecoxib vs nonsteroidal anti-inflammatory drugs for osteoarthritis and rheumatoid arthri- tis: the CLASS study: A randomized controlled trial. Celecoxib Long-term Arthritis Safety Study. JAMA. 284:1247-1255.

13. Qi, Z., et al. 2002. Opposite effects of cyclooxygenase- 1 and -2 activity on the pressor response to angiotensin II. J. Clin. Invest. 110:61-69. doi:10.1172/JCI200214752.

14. McAdam, B.F., et al. 1999. Systemic biosynthesis of prostacyclin by cyclooxygenase (COX)-2: the human pharmacology of a selective inhibitor of COX-2. Proc. Natl. Acad. Sci. U. S. A. 96:272-277.

15. Cheng, Y., et al. 2002. Role of prostacyclin in the cardiovascular response to thromboxane A2. Science. 296:539-541.

16. Mukherjee, D., Nissen, S.E., and Topol, E.J. 2001. Risk of cardiovascular events associated with selective COX-2 inhibitors. JAMA. 286:954-959.

17. FitzGerald, G.A., and Patrono, C. 2001. The coxibs, selective inhibitors of cyclooxygenase-2. N. Engl. J. Med. 345:433-442.

18. Fujino, T., et al. 2004. Decreased susceptibility to renovascular hypertension in mice lacking the prostaglandin $\mathrm{I}_{2}$ receptor IP. J. Clin. Invest. 114:805-812. doi:10.1172/JCI200421382.

19. Gerber, J.G., et al. 1978. Prostaglandins and renin release: II. Assessment of renin secretion following infusion of PGI2,E2 and D2 into the renal artery of anesthetized dogs. Prostaglandins. 15:81-88.

20. Narumiya, S., Sugimoto, Y., and Ushikubi, F. 1999. Prostanoid receptors: structures, properties, and functions. Physiol. Rev. 79:1193-1226.

21. Kopp, U.C., and DiBona, G.F. 1993. Neural regulation of renin secretion. Semin. Nephrol. 13:543-551.

22. Bock, H.A., Hermle, M., Brunner, F.P., and Thiel, G. 1992. Pressure dependent modulation of renin release in isolated perfused glomeruli. Kidney Int. 41:275-280.

23. Gerber, J.G., Keller, R.T., and Nies, A.S. 1979. Prostaglandins and renin release: the effect of PGI2, PGE2, and 13,14-dihydro PGE2 on the baroreceptor mechanism of renin release in the dog. Circ. Res. 44:796-799.

24. Carey, R.M., McGrath, H.E., Pentz, E.S., Gomez, R.A., and Barrett, P.Q. 1997. Biomechanical coupling in renin-releasing cells. J. Clin. Invest. 100:1566-1574.

25. Osborn, J.L., Kopp, U.C., Thames, M.D., and DiBona, G.F. 1984. Interactions among renal nerves, prostaglandins, and renal arterial pressure in the regulation of renin release. Am. J. Physiol. 247:F706-F713.

26. Jensen, B.L., and Kurtz, A. 1997. Differential regulation of renal cyclooxygenase mRNA by dietary salt intake. Kidney Int. 52:1242-1249.

27. Oida, H., et al. 1995. In situ hybridization studies of prostacyclin receptor mRNA expression in various mouse organs. Br. J. Pharmacol. 116:2828-2837.

28. Lorenz, J.N., Greenberg, S.G., and Briggs, J.P. 1993. The macula densa mechanism for control of renin secretion. Semin. Nephrol. 13:531-542.

29. Bell, P.D., Lapointe, J.Y., and Peti-Peterdi, J. 2003. Macula densa cell signaling. Annu. Rev. Physiol. 65:481-500.

30. Harris, R.C., and Breyer, M.D. 2001. Physiological regulation of cyclooxygenase- 2 in the kidney. Am.J. Physiol. Renal Physiol. 281:F1-F11.

31. Peti-Peterdi, J., et al. 2003. Luminal $\mathrm{NaCl}$ delivery regulates basolateral PGE2 release from macula densa cells. J. Clin. Invest. 112:76-82. doi:10.1172/ JCI200318018.

32. Yang, T., et al. 2000. Low chloride stimulation of prostaglandin E2 release and cyclooxygenase-2 expression in a mouse macula densa cell line. J. Biol. Chem. 275:37922-37929. 